\title{
Estaquia de clones de aceroleira em substrato comercial e areia
}

\author{
Rebeca Pereira Brandão ${ }^{1}$, Maurício Dominguez Nasser ${ }^{2}$, Lucas de Souza Silva ${ }^{1}$, Loyara Joyce de Oliveira ${ }^{3}$, \\ Giovanna Alencar Lundgren ${ }^{4}$ \\ ${ }^{1}$ Graduando em Agronomia, Centro Universitário de Adamantina - UniFAl. ${ }^{2}$ Pesquisador Científico, Polo \\ Regional Alta Paulista, Agência Paulista de Tecnologia dos Agronegócios - APTA. ${ }^{3}$ Engenheira Agrônoma, \\ Faculdade de Ciências Agrárias e Tecnológicas - Câmpus de Dracena - UNESP. ${ }^{4}$ Doutoranda em Ciências da \\ Nutrição - Universidade Federal da Paraíba. E-mail: rebecabrandao14@hotmail.com
}

\section{Resumo}

O domínio do método de propagação é fundamental, tanto para o profissional que trabalha com o melhoramento genético, como para o produtor e a indústria, por assegurar a formação de plantios uniformes de aceroleira e de qualidade. Com isso objetivou-se avaliar a propagação clones de aceroleira por estaquia utilizando substratos de areia e substrato comercial Carolina no município de Adamantina, SP. O experimento foi instalado no viveiro experimental da APTA Regional Alta Paulista em Adamantina-SP. Os tratamentos foram cinco clones de aceroleira: 1- Olivier, 2- Frutacor (BRS 238), 3- Cereja (BRS 236), 4Mirandópolis e 5- Okinawa, sendo acondicionados em dois tipos de substratos: areia lavada e substrato comercial Carolina ${ }^{\circ}$ O delineamento utilizado foi inteiramente casualizado e esquema fatorial com 5 clones e 2 substratos, totalizando 10 tratamentos e 4 repetições. Os dados foram submetidos à análise de variância pelo teste de $\mathrm{F}$, e as médias foram comparadas pelo teste de Tukey a $5 \%$ de probabilidade. Não se recomenda a propagação por estaquia para o clone Okinawa. Além da areia, o substrato Carolina pode ser utilizado para propagação de aceroleira através do método da estaquia.

Palavras-chave: acerola; produção de mudas; propagação.

\section{Scion of clays of acerola in commercial substrate and sand}

\begin{abstract}
The mastery of the propagation method is fundamental for both professionals working with genetic improvement, as well as for the producer and industry, to ensure the formation of uniform and quality plantations. The objective of this study was to evaluate the propagation of acerola tree clones by cutting using sand substrates and Carolina commercial substrate in the municipality of Adamantina, SP. The experiment was installed in Regional Research Alta Paulista Pole- Regional APTA experimental nursery in Adamantina-SP. The treatments were five clones of acerola tree: 1-Olivier, 2-Frutacor (BRS 238), 3-Cherry (BRS 236), 4-Mirandópolis and 5-Okinawa, being packaged in two types of substrates: washed sand and commercial substrate Carolina ${ }^{\circ}$. The design was completely randomized and a factorial scheme with 5 clones and 2 substrates, totaling 10 treatments and 4 replicates. The data were submitted to analysis of variance by the $\mathrm{F}$ test, and the means were compared by the Tukey test at $5 \%$ probability. The propagation by cutting is not recommended for Okinawa clone. In addition to the sand, the Carolina substrate can be used for propagation of acerola by cutting method.
\end{abstract}

Keywords: acerola; seedling production; propagation.

\section{Introdução}

Desde a década de 90, a cultura da acerola (Malpighia emarginata Sessé e Mociño ex
DC.), tem sido opção de geração de renda e fixação do homem no campo. O fruto conquistou o mercado consumidor pelo elevado teor de 
ácido ascórbico, que segundo Jesus et al. (2016) alcançam valores de $4000 \mathrm{mg}$ por $100 \mathrm{~g}$ de polpa.

Originada da região norte da América do Sul até o sul do México, a aceroleira foi trazida para o Brasil a mais de 60 anos e atualmente, o país se destaca é o maior produtor mundial, com área estimada em 10000 ha e destaque para os Estados Bahia, Ceará, Paraíba, Pernambuco e São Paulo que juntos detém mais de $80 \%$ da produção nacional. $\mathrm{Na}$ região Nordeste predomina as cultivares Junko, Flor Branca, BRS Sertaneja, Costa Rica, Okinawa, Nikki, Coopama $\mathrm{N}^{\circ} 1$ e BRS Cabocla. Sertaneja, Flor branca e Okinawa, e no estado de São Paulo a cultivar Olivier e Waldy (MONDIN et al., 2010; RITZINGER; RITZINGER, 2011; SOUZA et al., 2013; FURLANETO; NASSER, 2015; NASSER et al., 2016).

Caracterizada como cultura perene, a aceroleira pode ser propagada pela semeadura direta, estaquia, enxertia, alporquia e mergulhia. Em escala comercial, a estaquia é o método de propagação mais utilizado em diversas espécies, e comparado às demais tecnologia de propagação pode ser considerada o mais prático e rápido, e ainda proporcionar maior precocidade na produção e a garantia na manutenção das características genéticas da planta matriz (CASTRO; KLUGE, 2003; BORGES et al., 2011). Esta técnica segue o princípio da totipotência, ou seja, através da divisão celular por mitose, os tecidos da planta podem se transformar em outro tecido existente dos diversos órgãos da mesma planta, e no caso da aceroleira, o tecido do ramo vegetativo inserido no ambiente sem luz por determinado período, pode se transformar em raízes (HARTMANN et al., 2018).

Para produção de mudas com qualidade nutricional e fitossanitária, necessita-se buscar materiais minerais e orgânicos como substrato, com propriedades físicas e químicas apropriadas, de fácil aquisição no entorno das proximidades do viveiro de produção e viável economicamente. A forma usual para a produção de mudas de aceroleira, geralmente, consiste no uso de misturas empíricas de materiais no substrato, cujas características físico-químicas, em sua maioria, são desconhecidas (FARIAS et al., 2012; LIMA et al., 2005). O domínio do método de propagação é fundamental, tanto para o profissional que trabalha com o melhoramento genético, como para o produtor e a indústria, por assegurar a formação de plantios uniformes de aceroleira e posteriormente na produção de frutos com qualidade (GOMES et al., 2000).
Com isso objetivou-se avaliar a propagação de diferentes variedades de clones de aceroleira por estaquia, utilizando substratos de areia e substrato comercial Carolina ${ }^{\circ}$ no município de Adamantina, SP.

\section{Material e Métodos}

$O$ experimento foi instalado no viveiro experimental da APTA Regional Alta Paulista em Adamantina-SP, utilizando como câmara úmida uma estrutura metálica em arco $(2,50 \mathrm{~m}$ de comprimento, $1,45 \mathrm{~m}$ de largura e altura máxima de $1,20 \mathrm{~m}$ ), revestida de plástico transparente e sobre essa proteção plástica, tela de sombreamento de $50 \%$. No interior da câmara instalou-se irrigação por microaspersão em altura aproximada de $30 \mathrm{~cm}$ do nível do solo. Os tratamentos foram cinco clones de aceroleira: 1 Olivier, 2- Frutacor (BRS 238), 3- Cereja (BRS 236), 4- Mirandópolis e 5- Okinawa, sendo acondicionados em dois tipos de substratos: areia lavada e substrato comercial Carolina . A areia e o substrato comercial foram obtidos no comércio do município. Segundo fabricante, o substrato Carolina (acondicionado em sacos com capacidade mínima de $8 \mathrm{Kg}$ e volume aproximado de 45 L) é composto de turfa sphagno, vermiculita expandida, calcário dolomítico, gesso agrícola e fertilizante NPK (traços), e apresenta as seguintes propriedades: $\mathrm{pH}$ de 5,0 a 6,0 , condutividade elétrica de 0,4 a $1,0 \mathrm{mS} \mathrm{cm}$, densidade de $145 \mathrm{~kg} / \mathrm{m}^{3}$, capacidade de retenção de água (CRA 10) igual a 55\%, umidade máxima de $50 \%$, e não apresenta especificação granulométrica.

As estacas foram retiradas no início de novembro de 2014, da região apical dos ramos de plantas matrizes com bom estado nutricional e fitossanitário. Foram selecionadas estacas semilenhosas, com aproximadamente $20 \mathrm{~cm}$ de comprimento, e as folhas foram destacadas, deixando-se no máximo dois pares por estaca na região do ápice.

Em câmara úmida, as estacas foram enterradas em um terço do seu comprimento sobre os substratos. Após 60 dias do plantio foram avaliadas as seguintes características: porcentagem de estacas enraizadas considerando - enraizamento como a presença de raízes emitidas pela região da estaca enterrada no substrato, o número de raízes primárias através da contagem manual de raízes emitidas diretamente da estaca, e o comprimento em $\mathrm{cm}$ da maior raiz emitida de cada estaca. 
O delineamento experimental utilizado foi inteiramente casualizado em esquema fatorial com 5 clones e 2 substratos, totalizando dez tratamentos e quatro repetições, sendo 5 mudas por parcela experimental. Os dados foram submetidos à análise de variância pelo teste de $F$, e as médias foram comparadas pelo teste de Tukey a $5 \%$ de probabilidade. Para os dados em porcentagem, utilizou-se a transformação arcoseno da raiz quadrada de $x / 100$, e para as demais variáveis os dados foram transformados em raiz quadrada de $x+0,5$ (PIMENTEL-GOMES, 1990).

\section{Resultados e Discussão}

Não houve interação entre os substratos utilizados e as estacas dos clones de aceroleira, para as variáveis de porcentagem de estacas enraizadas e número de raízes primárias (Tabela 1). Pode-se observar que o clone Okinawa obteve $2,5 \%$ de estacas enraizadas, valor menor que os clones Olivier (muito cultivado na região do oeste paulista), Frutacor e Cereja; e não diferiu estatisticamente do clone Mirandópolis. Provavelmente fatores genéticos, fisiológicos e idade da planta matriz, além da posição da coleta das estacas existentes nas estacas das cultivares Olivier, Frutacor, Cereja associado ou não à época do ano de coleta das estacas (plena produção), e às condições de temperatura e umidade da câmara úmida interferiram significativamente no desenvolvimento das mudas quando comparado ao clone Okinawa. Estes valores de estacas enraizadas demonstram como o genótipo de cada cultivar pode influenciar o enraizamento na propagação da acerola por estaquia.
Nota-se também na Tabela 1 que a cultivar Olivier atingiu 52,50 \% de estacas enraizadas e sem adição de regulador vegetal para aumentar ou garantir o enraizamento. Este valor foi semelhante ao de Gontijo et al. (2003), onde os autores relataram valor máximo de $50 \%$ de enraizamento ao aplicar em cultivar de aceroleira sem identificação genética, $2800 \mathrm{mg}$. L' ${ }^{1}$ de ácido indolbutírico (AIB), com estacas de 15 $\mathrm{cm}$ contendo dois pares de folhas. Porém as estacas da cv. Olivier do presente trabalho enraizaram abaixo do valor apresentado por Lima et al. (2006), que trabalharam com plantas da progênie 91 com 2,5 anos de idade, e encontraram 83,33 \% de enraizamento em estacas de $15 \mathrm{~cm}$ retiradas da porção apical.

Em Anonáceas, Scaloppi Júnior e Martins (2014) relataram diferentes resultados no enraizamento de estacas, mesmo quando foi realizada com a mesma espécie. Ainda com relação a este método, os autores ressaltaram alguns fatores que podem interferir significativamente no sucesso desta propagação vegetativa: espécie, cultivar, ambiente de enraizamento, época do ano, planta-matriz, reguladores vegetais, e juvenilidade. Dutra et al. (2002), estudaram o enraizamento de estacas em pessegueiro, e notaram diferentes resultados entre cultivares, sendo que os melhores valores de estacas enraizadas e número de raízes por estaca foram na primavera e verão, mesma época de coleta das estacas do presente trabalho.

Tabela 1. Porcentagem de estacas enraizadas e número de raízes primárias em clones de aceroleira propagados por estaquia após 60 dias do plantio. Adamantina-SP, Janeiro de 2015.

\begin{tabular}{ccc}
\hline Tratamentos & Estacas enraizadas (\%) & Número de raízes primárias \\
\hline Olivier & $52,50 \mathrm{a}$ & $2,70 \mathrm{a}$ \\
Frutacor & $47,50 \mathrm{a}$ & $2,43 \mathrm{a}$ \\
Cereja & $25,00 \mathrm{a}$ & $1,33 \mathrm{ab}$ \\
Mirandópolis & $20,00 \mathrm{ab}$ & $1,25 \mathrm{ab}$ \\
Okinawa & $2,50 \mathrm{~b}$ & $0,05 \mathrm{~b}$ \\
\hline Média geral & 29,50 & 1,55 \\
CV(\%) & 48,76 & 30,30 \\
\hline
\end{tabular}

**Médias seguidas de letras diferentes minúsculas na coluna diferem significativamente pelo Teste de Tukey a $1 \%$.

Houve interação significativa no número de raízes primárias e comprimento da raiz maior entre os clones de aceroleira tanto em areia como no substrato Carolina (Tabela 2). Pode-se observar que os clones de aceroleira não apresentaram diferenças significativas quanto ao comprimento da maior raiz no substrato Carolina e areia, com exceção do clone Frutacor que resultou maior comprimento da raiz no substrato Carolina. Porém, na média geral o 
comprimento da raiz maior foi de $3,44 \mathrm{~cm}$ no substrato comercial contra $1,78 \mathrm{~cm}$ na areia, que provavelmente por sua composição ao natural, seja a mais deficiente em nutrientes, e provavelmente a capacidade de troca catiônica (CTC) do substrato Carolina seja significativamente maior a areia. Os tratamentos Olivier e Frutacor apresentaram raiz mais vigorosa que Cereja, Mirandópolis e Okinawa no substrato Carolina .

Tabela 2. Valores médios de comprimento da maior raiz de clones de aceroleira propagados por estaquia após 60 dias do plantio em substratos de areia e Carolina ${ }^{\circ}$. Adamantina-SP, Janeiro de 2015.

\begin{tabular}{|c|c|}
\hline \multicolumn{2}{|l|}{ Tratamentos } \\
\hline Olivier & 4,17 a $A$ \\
\hline Frutacor & 1,66 ab B \\
\hline Cereja & $1,83 a b A$ \\
\hline Mirandópolis & $1,06 a b A$ \\
\hline Okinawa & $0,20 \mathrm{~b} \mathrm{~A}$ \\
\hline \multicolumn{2}{|l|}{$\mathrm{CV}(\%)$} \\
\hline Média geral & 1,78 \\
\hline \multicolumn{2}{|c|}{$\begin{array}{l}\text { *Médias seguidas de letras diferentes minúsculas na } \\
\text { Teste de Tukey a } 5 \% \text {. }\end{array}$} \\
\hline $\begin{array}{l}\text { Na Tabela } \\
\text { apresentou valor } \\
\text { significativamente me } \\
\text { Estes resultados suge } \\
\text { desenvolve de fo } \\
\text { propagada por estaqu } \\
\text { com a propagação } \\
\text { avaliando, por exempl } \\
\text { épocas do ano, além } \\
\text { et al. (2014) encontra } \\
\text { de pegamento de mu } \\
\text { em diferentes porta-e }\end{array}$ & $\begin{array}{l}\text { que a Okinawa } \\
\text { nte nulo, e } \\
\text { clone Olivier. } \\
\text { Okinawa não se } \\
\text { quada quando } \\
\text { ita mais estudos } \\
\text { e dos demais } \\
\text { ia em diferentes } \\
\text { enxertia. Nasser } \\
\text { s acima de } 80 \% \\
\text { nawa enxertada }\end{array}$ \\
\hline
\end{tabular}

\section{Conclusões}

Clones de aceroleira propagados por estaquia apresentam diferentes resultados de enraizamento. Não se recomenda a propagação por estaquia para o clone Okinawa. Além da areia utilizada como substrato para produção inicial de mudas de aceroleira, o substrato Carolina pode ser recomendado para propagação de aceroleira através do método da estaquia.

\section{Referências}

BORGES, S. R.; XAVIER, A. L. S.; MELO, L. A.; ROSADO, A. M. Enraizamento de miniestacas de clones híbridos de Eucalyptus globulus. Revista Árvore, Viçosa, v. 35, n. 3, p. 425-434, 2011.
https://doi.org/10.1590/S0100$\underline{67622011000300006}$

CASTRO, P. R. C.; KLUGE, R. A. Ecofisiologia de fruteiras: abacateiro, aceroleira, macieira, pereira e videira. Piracicaba: Editora Agronômica Ceres, 2003. $136 \mathrm{p}$.

DUTRA, L. F.; KERSTEN, E.; FACHINELLO, J. C. Época de coleta, ácido indolbutírico e triptofano no enraizamento de estacas de pessegueiro. Scientia Agrícola, Piracicaba, v. 59, n. 2, p. 327333, 2002. http://dx.doi.org/10.1590/S0103$\underline{90162002000200019}$

FARIAS, W. C.; OLIVEIRA, L. L. P.; OLIVEIRA, T. A.; DANTAS, L. L. G. R; SILVA, T. A. G. Caracterização física de substratos alternativos para produção de mudas. Agropecuária Científica no Semi-Árido, Campina Grande, v. 8, n. 3, p.1-5, 2012.

FURLANETO, F. P. B.; NASSER, M. D. Panorama da cultura da acerola no estado de São Paulo. Pesquisa \& Tecnologia, v. 12, n. 1, 2015. Disponível em:

http://www.aptaregional.sp.gov.br/acesse-osartigos-pesquisa-e-tecnologia/edicao2015/ianeiro-junho-3/1637-panorama-da- 
cultura-da-acerola-no-estado-de-sao-

paulo/file.html?force download=1. Acesso em: 31 maio 2016.

GOMES, J. E.; PERECIN, D.; MARTINS, A. B. G.; IGNÁCIO, N. Enraizamento de estacas herbáceas de genótipos de acerola em câmara de nebulização intermitente tratadas com ácido indolbutírico em duas épocas. Revista Brasileira de Fruticultura, Jaboticabal, v. 22, n. 3, p. 407412, 2000.

GONTIJO, T. C. A. et al. Enraizamento de diferentes tipos de estacas de aceroleira utilizando ácido indolbutírico. Revista Brasileira de Fruticultura, Jaboticabal, v. 25 , n. 2 , p. 290292, 2003. https://doi.org/10.1590/S010029452003000200027

HARTMANN, H. T.; KESTER, D. E.; DAVIES JÚNIOR, F. T.; GENEVE, R. L. WILSON, S. B. Plant propagation: principles and practices. 9.ed. New Jersey: Prentice Hall, 2018. 1024 p.

JESUS, A. M.; CASTRO, J. M. C.; DIAS, M. S. C. Doenças da aceroleira. Informe Agropecuário, Belo Horizonte, v. 37, n. 290, p. 16-21, 2016.

LIMA, R. L. S; SIQUEIRA, D. L.; WEBER, O. B.; BUENO, D. M.; CECON, P. R. Enraizamento de estacas caulinares de acerola em função da composição do substrato. Semina: Ciências Agrárias, Londrina, v. 26, n. 1, p. 27-32, 2005. https://doi.org/10.5433/1679-

$\underline{0359.2005 v 26 n 1 p 27}$

LIMA, R. L. S.; SIQUEIRA, D. L.; WEBER, O. B.; CAZETTA, J. O. Comprimento de estacas e parte do ramo na formação de mudas de Aceroleira, Revista Brasileira de Fruticultura, Jaboticabal, v. 28, n. 1, p. 83-86, 2006.

https://doi.org/10.1590/s0100-

$\underline{29452006000100024}$

MONDIN, M.; OLIVEIRA, C. A.; VIEIRA, M. L. C. Karyotype characterization of Malpighia emarginata (Malpighiaceae). Revista Brasileira de Fruticultura, Jaboticabal, v. 32, n. 2, p. 369374, 2010. http://dx.doi.org/10.1590/S0100$\underline{29452010005000072}$

NASSER, M. D.; CORRÊA, L. S.; CAVICHIOLI, J. C.; MARIANO, F. A. C.; VITORINO, R. A. Enxertia por garfagem em mudas de aceroleira cv. Okinawa sobre diferentes porta-enxertos. Cultura Agronômica, Ilha Solteira, v. 23, n. 1, p. 63-70, 2014.

NASSER, M. D.; MARIANO-NASSER, F. A. C.; FURLANETO, F. P. B. Panorama nacional da produção de acerola. Revista Campo e Negócios - HF, Uberlândia, v. 8, n. 133, p. 60-63, 2016.

PIMENTEL-GOMES, F. Curso de estatística experimental. Piracicaba: Nobel, 1990. 468 p.

SCALOPPI JÚNIOR, E. J.; MARTINS, A. B. G. Estaquia em Anonas. Revista Brasileira de Fruticultura, Jaboticabal, v. 36, ed. esp., p. 147156, 2014. http://dx.doi.org/10.1590/S010029452014000500018

SOUZA, F. F.; DEON, M. D.; CASTRO, J. M. C.; LIMA, M. A. C.; RYBKA, A. C. P.; FREITAS, S. T. Principais variedades de aceroleiras cultivadas no Submédio do Vale do São Francisco. Petrolina: Embrapa Semiárido, 2013. 21 p. (Série Embrapa Semiárido. Documentos, 255). Disponível em: http://ainfo.cnptia.embrapa.br/digital/bitstream/ item/99018/1/SDC255.pdf. Acesso em: 18 nov. 2019. 